OPEN ACCESS

Edited by:

Oliver Adunka

The Ohio State University Columbus,

United States

Reviewed by:

Brian Richard Earl,

University of Cincinnati, United States

Bryan Kevin Ward, Johns Hopkins School of Medicine,

United States

*Correspondence:

Jeremy Hornibrook jeremy@jhornibrook.com

Specialty section:

This article was submitted to Auditory Cognitive Neuroscience,

a section of the journal

Frontiers in Neuroscience

Received: 23 December 2016 Accepted: 15 May 2017

Published: 16 June 2017

Citation:

Hornibrook J (2017) Tone Burst Electrocochleography for the Diagnosis of Clinically Certain Meniere's Disease.

Front. Neurosci. 11:301. doi: 10.3389/fnins.2017.00301

\section{Tone Burst Electrocochleography for the Diagnosis of Clinically Certain Meniere's Disease}

\author{
Jeremy Hornibrook * \\ Department of Otolaryngology-Head and Neck Surgery, Christchurch Hospital, University of Canterbury and University of \\ Otago, Christchurch, New Zealand
}

The technique of transtympanic electrocochleography was initially developed as an objective hearing threshold test by Eggermont. Gibson et al. (1977) claimed that an enlarged direct current component of the action potential (AP) called the summating potential (SP) is an indication of endolymphatic hydrops, later confirmed by Coates who proposed an SP/AP ratio measure. This led to numerous publications using diagnostic ratios of $0.33-0.35$. The insensitivity led to an eventual disenchantment with the test as a reliable objective test for Meniere's disease. It was further confused by audiologists employing remote canal or ear drum electrodes which give a response about one-fourth of the magnitude obtained by an electrode in contact with the cochlea. Subsequently Gibson stated that an SP/AP ratio of $<0.5$ is not diagnostic for hydrops. He then showed that a tone burst stimulus gave the test a significantly higher sensitivity and specificity, which has been supported by others. On MRI inner ear imaging with gadolinium hydrops can be seen, but the quality of images and what is seen may vary according to brand of scanner, settings, mode of gadolinium administration, and the possibility that gadolinium entry may favor the vestibule. Transtympanic tone burst electrocochleography is to date the simplest, cheapest and most sensitive technique for detecting cochlear endolymphatic hydrops to confirm a diagnosis of Meniere's disease.

Keywords: Meniere's disease, electrocochleography, tone bursts, transtympanic EcochG, clinically certain Meniere's disease

\section{INTRODUCTION}

Electrocochleography (EcochG) is a method of directly recording electrical activity of the cochlea and the acoustic nerve in response to acoustic stimulation. The three components measurable are the cochlear microphonic (CM), the action potential (AP), and the summating potential (SP). In contrast to the earliest studies, new computer averaging techniques have enabled routine testing of these components in humans.

This review will briefly summarize the useful components of the EcochG used in the diagnosis of Meniere's disease. The effects of electrode placement on the size of the AP and SP and the merits of tone burst stimuli will be discussed. New international criteria for the symptomatic diagnosis of Meniere's disease make no allowance for any diagnostic test for a disorder which always begins in the cochlea, even though objective testing can confirm or exclude it. 


\section{COCHLEAR MICROPHONIC}

The CM, originally called the cochlear potential, was recorded in cats by Wever and Bray (1930). It is thought to be the summed microphonic from many hair cells recorded by a distant electrode. The lower the frequency of stimulation the larger the number of hair cells which will produce CMs in the same phase and the larger the $\mathrm{CM}$ will be. Although the $\mathrm{CM}$ has a number of new applications in auditory testing, its routine use is somewhat limited by the reduction in signal-to-noise ratio that occurs with a remote electrode.

\section{ACTION POTENTIAL}

The response from the acoustic nerve is the AP and was first demonstrated in the cochlear nerve and brainstem of cats by Saul and Davis (1932). Because of the concern that direct recording from the cochlea in individuals with normal hearing was dangerous, Ruben et al. (1961) measured APs in patients with hearing losses by a silver ball electrode placed in the round window niche after a typmanotomy and achieved the first intraoperative demonstration of hearing improvement during stapedectomy. In what was the first use of a remote electrode, Yoshie et al. (Yoshie, 1968) measured APs in normal hearing humans with a hypodermic needle shielded with a polyethylene tube inserted into the anesthetised posterior ear canal skin, about $5 \mathrm{~mm}$ from the annulus. In the same year Portmann (Portmann et al., 1967) demonstrated that it was safe to record from the round window niche with an electrode passed through the eardrum. In the USA fears of safety and litigation over transtympanic electrodes persist to this day.

A $100 \mathrm{~ms}$ click stimulus stimulates the whole basilar membrane. Frequency selective masking experiments suggest that the major contribution from a click is from the basal turn of the cochlea (Teas et al., 1962) from 10 to $4 \mathrm{kHz}$ as the traveling wave is progressively damped as it travels toward the apex (Zwicker and Fast, 1972). Also the velocity of the traveling wave along the basilar membrane slows as it approaches the apex of the cochlea, resulting in a decrease in hair cells firing per unit time (Zerlin, 1969). This limitation is being addressed by the study of an alternative "Chirp" stimulus which has more low frequency energy occurring earlier in the stimulus (Chertoff et al., 2010).

The initial application of AP recordings was the objective determination of hearing thresholds. As the signal is generated so close to the recording electrode, masking of the opposite ear is not necessary.

\section{SUMMATING POTENTIAL}

The SP is a direct current component of the AP, described independently in guinea pigs by Davis et al. (1950) who assumed it was a post-synaptic response. von Bekesy (1952) considered it to be a shift of the CM. The CM was thought to be derived from the outer hair cells and the SP from the inner hair cells. However, it is present in pigeon ears which lack inner hair cells (Stopp and
Whitfeild, 1964). The SP is now assumed to be a result of cochlear microphonic distortions (Dallos et al., 1972).

The maximum $\mathrm{CM}$ is recorded closest to maximum hair cell displacement, whereas the SP is maximum at a point where the summed effect from a large area of basilar membrane can be recorded. In endolymphatic hydrops the downward vibration of the basilar membrane is limited as it is being stretched, so the normal up-going asymmetry is enhanced, leading to a SP of increased amplitude (Gibson, 1978).

The SP became to be of interest as an indicator of endolymphatic hydrops, and therefore in the objective diagnosis of Meniere's disease.

\section{SUMMATING POTENTIAL IN MENIERE'S DISEASE}

Schmidt et al. (1974) noted that the SP in Meniere's disease from tone bursts is about five times larger than in patients with high frequency hearing loss. Eggermont (1979) found that short 4 $\mathrm{kHz} 4 \mathrm{~ms}$ tone pips elicit a small AP which limits their use for diagnosing Meniere's disease compared with a click stimulus (Gibson, 1978).

Gibson et al. (1977), using transtympanic EcochG with clicks, found a large DC potential causing a widening of SP/AP waveform that might be a useful indicator of Meniere's disease. There was a high correlation with the symptomatic likelihood of Meniere's disease. Moffat et al. (1978) achieved a decrease in the negative SP in 11/13 patients after oral glycerol dehydration, with no significant change in the pure tone audiogram or speech discrimination. This was suggested as being a useful indicator of prognosis in endolymphatic sac surgery.

Coats (1981a) found that Meniere's ears had a larger SP/AP ratio compared with non-Meniere's ears, when recorded using a canal electrode and a click stimulus. There was also a correlation between a large SP/AP ratio in ears with reduced caloric responses in comparison with a small SP/AP ratio in ears with normal caloric responses (Coats, 1981b).

A major issue of contention for the EcochG has been the magnitude and quality of responses depending on the type and placement of the active electrode.

\section{ELECTRODE PLACEMENT}

The majority of publications on click stimulus in Meniere's ears have been by audiologists using distant electrodes which, because of their distance, require more signal averaging to cancel out random noise, and produce far smaller responses.

Ferraro et al. (1986) compared the responses and comfort of three ear canal electrodes.

Of the three there was no difference in comfort. A disposable soft insulated ear canal foam plug electrode design with a central sound-conducting tube was the easiest to place and gave the best responses. Sohmer and Feinmesser (1967) recorded the AP in cats with silver ball electrode in the round window niche and the ear drum and from a subdermal needle and a clip on the ear lobe. $\mathrm{He}$ found that the AP recorded from the round window niche 
was 10-25 times larger than the AP recorded from the other three sites.

Roland et al. (1995) compared responses from a transtympanic electrode (TT) with an ear canal (EAC) electrode in 19 healthy volunteers. The click responses from a TT electrode were seven times the magnitude as those from a EAC electrode. In a further study 50 ear canal EcochG tracings interpreted by 10 different audiologists revealed statistically significant interinterpreter differences between no response and very difficult to read SP/AP ratios (Roland and Roth, 1997). He emphasized the implications for diagnosis and its reliability in investigational studies.

\section{CLICK SP/AP STUDIES IN MENIERE'S DISEASE}

Gibson et al. (1983) performed click stimulus EcochG in 44 Meniere's ears and in 32 normal ears and 40 ears with sensorineural hearing loss. A SP/AP ratio of 0.30 clearly separated them, providing the loss exceeded an average of $40 \mathrm{dBHL}$.

The click SP/AP ratio as a diagnostic test for Meniere's disease became of world-wide interest and the basis of numerous publications, some of which are listed in Table 1. The highest sensitivity of $85 \%$ was achieved by Camilleri and Howarth (2001) with an SP/AP ratio of 0.33 . In contrast Gibson et al. (Gibson, 2005) reported a $40 \%$ sensitivity with an SP/AP ratio of 0.47 . The explanation for this will follow. In addition to a click SP/AP ratio Ferraro and Tibbils (1999) recorded the AP using an ET electrode. He advocated the addition of an SP/AP area ratio (Ferraro and Tibbils, 1999) to improve the sensitivity and specificity to 92 and $84 \%$, respectively (Al-momani et al., 2009). However, Marcio et al. (transtympanic) (Marcio et al., 2006) and Ikino et al. (transtympanic) (Ikino and de Almeida, 2006) could not confirm it.

A significant advance in the EcochG sensitivity for diagnosing definite Meniere's disease has come from the use of tone burst stimuli.

\section{TONE BURST STUDIES IN MENIERE'S DISEASE}

In 1986 Dauman et al. (Dauman et al., 1986, 1998) measured the effect of glycerol on ears tested transtympanically with free field tone bursts of octave frequencies between 1 and $8 \mathrm{kZ}$ at $90 \mathrm{~dB} \mathrm{HL}$, which produced a prolonged SP whose magnitude was measured in microvolts from its midpoint to the baseline. Long tone bursts in patients with Meniere's disease showed significantly larger SPs than in control subjects, with most Meniere's ears having an SP decrease observed after dehydration.

In 1990, at the Third International Symposium and Workshops on Surgery of the Inner Ear, Dauman and Aran (1991) expanded their experience, comparing clicks vs. $10 \mathrm{~ms}$ tone bursts. The responses to $1,2,4$, and $8 \mathrm{Kz}$ TBs are shown in Figure 1, with $8 \mathrm{kHz}$ usually being positive. The mean amplitudes for those frequencies are shown in Figure 2, showing 1 and $2 \mathrm{kHz}$ are the most sensitive for indicating hydrops.
TABLE 1 | SP/AP ratio criteria from extratympanic (ET) and transtympanic (TT) EcochG studies with a click stimulus.

\begin{tabular}{lllll}
\hline Authors & Electrode & $\begin{array}{c}\text { SP/AP } \\
\text { criterion }\end{array}$ & $\begin{array}{c}\text { Sensitivity } \\
\mathbf{( \% )}\end{array}$ & $\begin{array}{c}\text { Specificity } \\
\text { (\%) }\end{array}$ \\
\hline Mori et al., 1987 & ET & 0.44 & 68 & \\
Aso, 1991 & TT & 0.37 & 58 & 94 \\
Pou et al., 1996 & ET & 0.35 & 57 & 95 \\
Filipo et al., 1997 & TT & 0.43 & 64 & \\
& & 0.50 & 47 & 96 \\
Sass, 1998 & TT & 0.41 & 62 & 97 \\
Ferraro and Tibbils, 1999 & ET & 0.41 & 60 & \\
Camilleri and Howarth, 2001 & TT & 0.33 & 85 & \\
Chung et al., 2004 & ET & 0.34 & 71 & \\
Gibson, 2005 & TT & 0.47 & 40 & \\
Marcio et al., 2006 & Tा & 0.37 & 52 & \\
Takeda and Kakigi, 2010 & ET & 0.40 & 56 & \\
Claes et al., 2011 & TT & 0.35 & 56 & \\
\hline
\end{tabular}

Gibson (1991) compared clicks with $1 \mathrm{kHz} 12 \mathrm{~ms}$ tone bursts in 42 Meniere's ears and 48 normal sensorineural loss ears, with the symptomatic likelihood of Meniere's disease. At $90 \mathrm{~dB}$ HL a 1 $\mathrm{kHz}$ tone burst more negative than $3 \mathrm{mV}$ separated the Meniere's ears very precisely from the normal and sensorineural ears. The false negatives for tone bursts were half those for clicks.

At The First International Conference on EcochG, Otoacoustic Emissions, and Intraoperative Monitoring Gibson (1993) expanded the comparison of clicks vs. tone bursts (12 $\mathrm{ms}$ ) for the diagnosis of endolymphatic hydrops in 1,101 ears by transtympanic EcochG. The $0.5,1,2,4$, and $8 \mathrm{kHz}$ tone burst diagnostic criteria are presented in Table 2.

Conlon and Gibson (2000) confirmed the superiority of tone bursts over clicks and with a $1 \mathrm{kHz}$ tone burst found hydrops in $10 \%$ of contralateral ears in Meniere's patients (Conlon and Gibson, 1999). Claes et al. (2011) used a transtympanic technique with $100 \mathrm{dBHL}$ tone bursts. He achieved a $91 \%$ sensitivity for implying hydrops in $91 \%$ of ears with an AAO-HNS definite diagnosis of Meniere's disease when the SP amplitude was more negative than $-3 \mathrm{mV}$ for $1 \mathrm{kHz}$ or more negative than $2 \mathrm{mV}$ in at least three tone burst frequencies.

Ferraro (Ferraro et al., 1994) found tone burst SPs measured with an extratympanic electrode were four times smaller compared with a transtympanic electrode. Bohlen et al. (1991) measured click and tone burst responses sequentially with an extratympanic and transtympanic electrode. In $90 \%$ of patients TT EcochG was equal to or more comfortable than for an ET electrode. Tone bursts with an ET electrode gave no response or were unreliably small.

In most EcochG studies on Meniere's ears the control ears have been Meniere's opposite ears or ears with normal hearing or ears with sensorineural hearing loss. To provide purer controls Gibson (2009) compared click and tone burst responses in 2,717 patients from Meniere's ears with ears with equivalent hearing. For a click SP/AP response there was no statistical difference between Meniere's ears and nonMeniere's ears. In a further analysis (Iseli and Gibson, 2010) a 

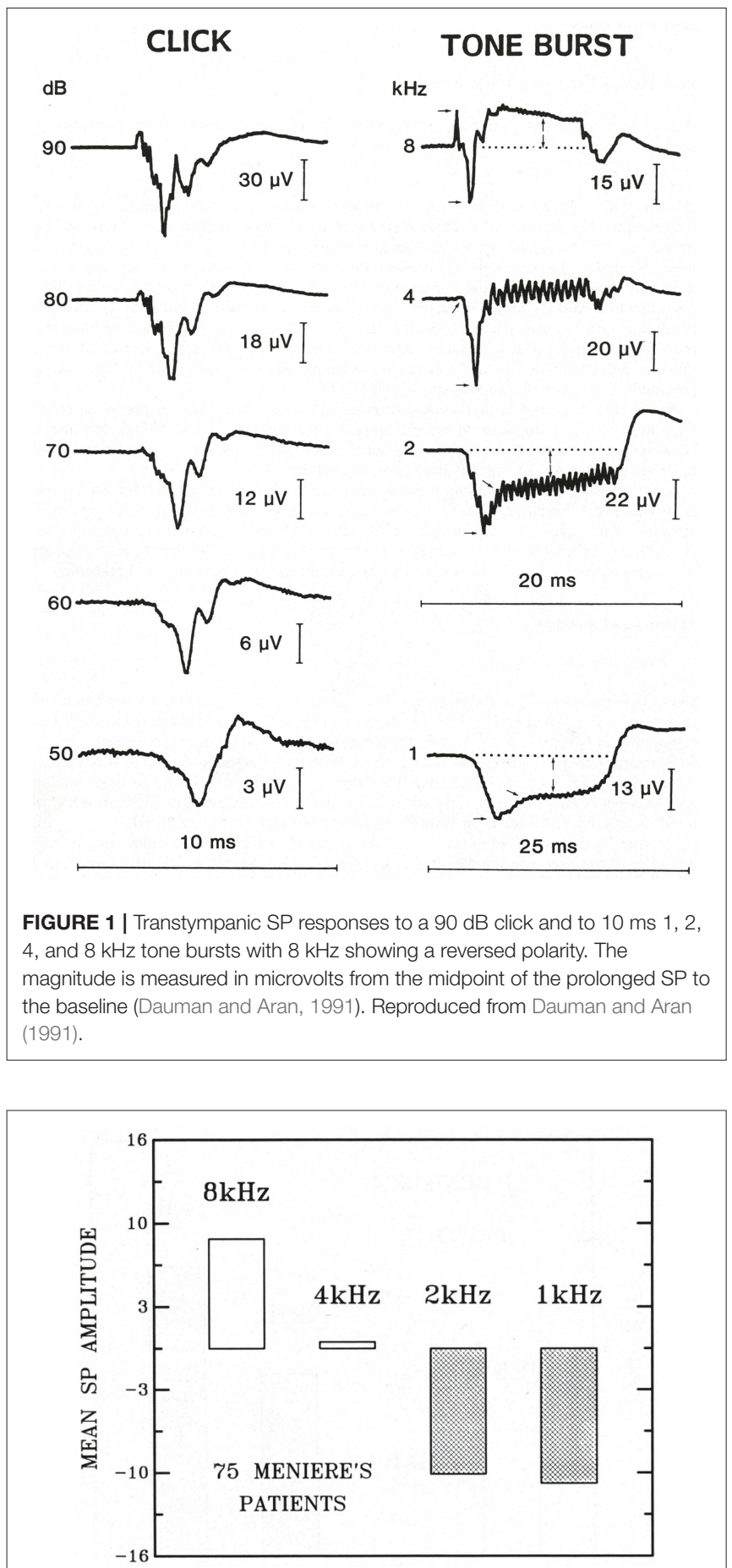

FIGURE 2 | The mean tone burst SP amplitudes (in $\mathrm{mV}$ ) in 75 Meniere's patients at 1, 2, 4, and $8 \mathrm{kHz}$, respectively (Dauman and Aran, 1991). Reproduced from Dauman and Aran (1991).

click stimulus had diagnostic sensitivity of $35 \%$ and specificity of $91 \%$ for an SP/AP ratio of not $<0.47$, compared with and $95 \%$ sensitivity and $79 \%$ sensitivity for combination of $1 \mathrm{kHz}$ tone burst thresholds and a tone burst SP/AP ratio.
TABLE 2 | Diagnostic level for tone bursts to diagnose hydrops (Gibson, 1993).

\begin{tabular}{|c|c|c|}
\hline Hz of SP hearing level & dB HL & Diagnostic criterion (mV) \\
\hline \multicolumn{3}{|l|}{ MORE NEGATIVE THAN } \\
\hline \multirow[t]{4}{*}{500 HZ (85 dB HL) } & under 25 & -2 \\
\hline & 20-35 & -2 \\
\hline & $40-55$ & -2 \\
\hline & $60-75$ & -1 \\
\hline \multirow[t]{4}{*}{1 kHz (100 dB HL) } & under 25 & -6 \\
\hline & $20-25$ & -6 \\
\hline & $40-55$ & -6 \\
\hline & $60-75$ & -3 \\
\hline \multirow[t]{4}{*}{2 kHz (100 dB HL) } & under 25 & -9 \\
\hline & $20-35$ & -7 \\
\hline & $40-55$ & -5 \\
\hline & $60-75$ & -5 \\
\hline \multirow[t]{4}{*}{4 kHz (100dB HL) } & under 25 & -9 \\
\hline & 20-35 & -5 \\
\hline & $40-55$ & -5 \\
\hline & $60-75$ & -5 \\
\hline \multicolumn{3}{|l|}{ MORE POSITIVE THAN } \\
\hline \multirow[t]{4}{*}{8 kHz (100 dB HL) } & under 25 & +6 \\
\hline & 20-35 & +6 \\
\hline & $40-55$ & +6 \\
\hline & $60-75$ & +6 \\
\hline
\end{tabular}

The diagnostic level was chosen as the nearest whole figure to the level which provides a false rate of $5 \%$.

Despite significant advances in the sensitivity of electrophysiological testing official diagnostic classifications for Meniere's disease remain symptom-based.

\section{CURRENT DIAGNOSIS OF MENIERE'S DISEASE}

Since Prosper Meniere's first descriptions of the disorder in 1861 there was no recognized symptomatic classification until 1972 (Barber et al., 1972). The Equilibrium Committee of the American Academy of Otolaryngology-Head and Neck Surgery (AAO-HNS) has produced three diagnostic definitions, the most recent one in 1995 (Monsell et al., 1995) used internationally until 2015 (Table 3). The four categories were possible, probable, definite, and certain. AAO-HNS definite has been a universal diagnostic criterion for numerous clinical studies. The definition of certain was histopathological confirmation from a postmortem. The AAO-HNS has been and remains skeptical as to the reliability of any objective tests.

The Barany Society, an international vestibular disorders society based in Sweden, has embarked on a project to achieve worldwide agreement on precise definitions of vestibular symptoms and the symptomatic diagnosis of common vestibular disorders. To conform to The International Classification of Diseases the vestibular diagnoses are limited to probable and 
TABLE 3 | AAO-HNS Committee on Hearing and Equilibrium 1995 diagnostic criteria for Meniere's disease (Monsell et al., 1995).

CERTAIN MENIERE'S DISEASE
Definite Meniere's disease, plus histopathologic confirmation
DEFINITE MENIERE'S DISEASE
Two or more definitive spontaneous episodes of vertigo of 20 min or longer
Audiometrically documented hearing loss on at last one occasion
Tinnitus or aural fullness in the treated ear
Other causes excluded
PROBABLE MENIERE'S DISEASE
One definite episode of vertigo
Audiometrically documented hearing loss on at least one occasion
Tinnitus or aural fullness in the treated ear
Other causes excluded
POSSIBLE MENIERE'S DISEASE
Episodic vertigo of the Meniere type without documented hearing loss, or
Sensorineural hearing loss, fluctuating, or fixed, with disequilibrium but without
definitive episodes
Other causes excluded

definite. For definite Meniere's disease the new symptomatic criteria (Lopez-Escamez et al., 2015) are similar and a logical improvement on the AAO-HNS 1995 criteria (Table 4). Possible and certain no longer exist.

\section{OPINION ON THE VALIDITY OF ECOCHG FOR THE DIAGNOSIS OF MENIERE'S DISEASE}

Nguyen et al. (2010) conducted a survey among members of the American Otological Society and the American Neurotology Society as to their opinions on the usefulness of EcochG for diagnosing Meniere's disease. Approximately 70\% employed an extratympanic electrode and $30 \%$ a transtympanic electrode. Eighty-three percent said they would discount a result that was contradictory to their clinical impression, with $57 \%$ preferring an ENG caloric test and VEMPs for 27\%. Only 45\% used EcochG. The overall conclusion was that EcochG is perceived to have low clinical use and reliability, and among those who use it there is little consensus on technique and stimulus modality.

Kim et al. (2005) conducted a click EcochG study with an extratympanic electrode and an SP/AP diagnostic ratio of $>0.4$ on 97 patients with suspected Meniere's disease. Of 60 patients with an AAO-HNS symptomatic diagnosis of Meniere's disease $67 \%$ with a definite diagnosis and $53 \%$ with a less-than-definite diagnosis had a positive test. They concluded that, because of its lack of sensitivity, EcochG should not play a decisive role in determining the presence or absence of Meniere's disease.

\section{VESTIBULAR MENIERE'S DISEASE}

The term vestibular Meniere's disease is sometimes used (Paparella, 1984a,b; Paparella and Mancini, 1985). It originated in the earliest iteration of the AAO-HNS diagnostic criteria
TABLE 4 | The 2015 Barany Society diagnostic criteria for Meniere's disease (Lopez-Escamez et al., 2015).

\section{DEFINITE MENIERE'S DISEASE}

A. Two or more spontaneous episodes of vertigo, each lasting 20 min to $12 \mathrm{~h}$

B. Audiometrically low-to-medium-frequency sensorinerual hearing loss in one ear, defining the affected ear on at least one occasion, during or after one of the episodes of vertigo

C. Fluctuating aural symptoms (hearing, tinnitus, or fullness) in the affected ear

D. Not better accounted for by another vestibular diagnosis

\section{PROBABLE MENIERE'S DISEASE}

A. Two or more episodes of vertigo or dizziness, each lasting $20 \mathrm{~min}$ to $24 \mathrm{~h}$

B. Fluctuating aural symptoms (hearing, tinnitus, or fullness) in the affected ear

C. Not better accounted for by another vestibular diagnosis

(Barber et al., 1972), separating cochlear and vestibular forms, but abandoned in the 1995 criteria. Currently it has no official basis.

Dornhoffer and Arenberg (1993) studied 15 patients with recurrent vertigo attacks without fluctuating hearing they called vestibular Meniere's disease (or possible on the 1995 AAO-HNS criteria). On transtympanic tone burst Ecoch at 1 and $2 \mathrm{kHz}$ by their own criteria 6 were positive for hydrops, supporting a diagnosis of Meniere's disease.

With the abolition of the AAO-HNS certain Meniere's disease category (a post-mortem now rarely achievable) there is a need for alternative diagnostic certainty, particularly for investigational studies, and to unequivocally distinguish Meniere's disease from other causes of recurrent vertigo attacks.

\section{CLINICALLY CERTAIN MENIERE'S DISEASE}

The term clinically certain Meniere's disease can be defined as a diagnosis based on the 1995 AAO-HNS symptomatic criteria (Monsell et al., 1995) (or now probable and definite on the international Barany Society criteria (Lopez-Escamez et al., 2015) plus transtympanic electrocochleographic confirmation of endolymphatic hydrops, based on the most sensitive criteria for tone bursts and clicks.

Based on this definition Hornibrook (Hornibrook et al., 2010b, 2011; Johnson et al., 2016) and colleagues have conducted three studies on definite Meniere's disease patients in whom there was clinical certainty of the diagnosis. Objective proof of hydrops was established by transtympanic EcochG with tone bursts and clicks. The technique and settings are illustrated in Figure 3. The diagnostic tone burst criteria were at 1 and/or $2 \mathrm{kHz}$ (Table 2; Gibson, 1993) and/or a click SP/AP ratio of $>0.5$.

Since the discovery that an abnormally low threshold cervical vestibular evoked potential (cVEMP) could confirm a diagnosis of superior canal dehiscence syndrome other diagnostic applications for VEMPs have been sought, including for Meniere's disease with numerous publications employing cVEMPS and ocular VEMPs (oVEMPs) to diagnose hydrops in the vestibule. These have produced conflicting interpretations as to the diagnostic sensitivity. In 18 patients with a clinically certain diagnosis in one ear, Johnson et al. (2016) measured cVEMP 

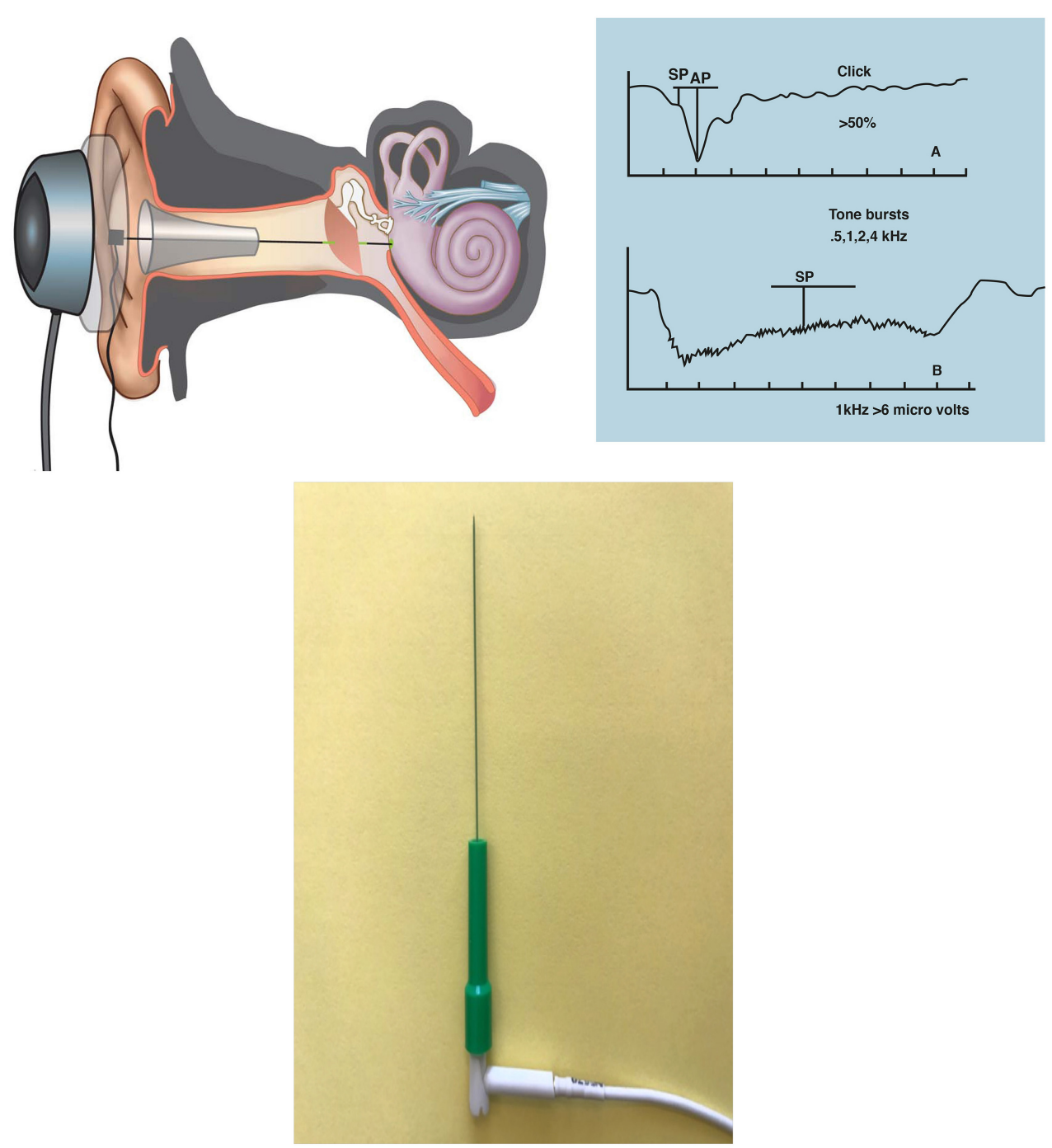

FIGURE 3 | Transtympanic EcochG for three studies on "clinically certain" Meniere's disease (Hornibrook et al., 2010b, 2011; Johnson et al., 2016). Local anesthesia is a tiny drop of phenol placed at 9 o'clock or 3 o'clock on the ear drum. An insulated needle is passed through the drum with its tip lying in the round window niche and secured by elastic bands to a circular bracket over the ear over which a headphone is placed. Stimuli were from an Amplaid mk15 diagnostic system. Clicks: 10 ms broadband alternating polarity clicks of $100 \mathrm{~ms}$ duration at $95 \mathrm{~dB} \mathrm{HL}$ at repetition rate of 11.3/s with 100-200 repetitions. Tone bursts: $1 \mathrm{and} 2 \mathrm{kHz} 100 \mathrm{~dB} \mathrm{HL}$ tone bursts with a $1 \mathrm{~ms}$ linear rise/fall and $14 \mathrm{~ms}$ plateau at a repetition rate of 30.1/s. The diagnostic criterion for clicks was an SP/AP ratio of $>0.5$, and for tone bursts criteria for 1 and $2 \mathrm{kHz}$ as in Table 2 (Gibson, 1991). From Hornibrook et al. (2012). Inset: TECA disposable monopolar needle $37 \mathrm{~mm} \times 28 \mathrm{G}$ (Natus Manufacturing Ltd., Gort, Galway, Ireland).

and oVEMP amplitude, latency and threshold in the Meniere's ear and their opposite ears and in the ears of 22 normal control ears. The overlap of results from the Meniere's patients compared with normal controls was such that VEMP abnormalities appear limited as a sole diagnostic test for Meniere's disease. As endolymphatic hydrops in Meniere's disease always starts in the cochlea (Pender, 2014) it would seem logical to employ the most sensitive test which confirms cochlear hydrops.

Confirmation of visible inner ear hydrops on MRI scanning with intratympanic gadolinium (Nakashima et al., 2009) has led to numerous MRI inner ear studies in the hope that a visible diagnosis of hydrops would be the standard by which other tests might be compared (Hornibrook et al., 2010a).
Hornibrook et al. (2015) compared the sensitivity of intratympanic gadolinium MRI with tone burst EcochG for diagnosing hydrops in 57 ears with AAO-HNS possible, probable, or definite Meniere's disease. In 30 patients with definite Meniere's disease the tone burst Ecoch G was positive in 83\%, the click in $30 \%$, and gadolinium MRI in $47 \%$. Although adequate imaging was achieved in $90 \%$ of scans, with tone burst EcochG was a more sensitive test for definite Meniere's disease and therefore for cochlear hydrops. Tone burst EcochG was also more sensitive than MRI for probable and possible Meniere's disease and in some cases, with visible vestibular hydrops, more sensitive for confirming cochlear hydrops. Ziylan et al. (2016) reviewed and compared this study with three other 
MRI/click-only EcochG studies with a low SP/AP diagnostic ratio of $>0.33$ which will have enhanced its apparent sensitivity. They concluded that there is a relative low sensitivity and predictive value for click stimulus EcochG compared with gadolinium inner ear MRI for detecting hydrops in Meniere's disease. Images and conclusions from MRI inner ear imaging appear confounded by variables such as scanner brand, head coil specifications, and the possibility that gadolinium entry may be variable and favor the vestibule (Hornibrook et al., 2016).

\section{SUMMARY AND CONCLUSION}

The initial promise of a click response SP/AP ratio as a sensitive test for endolymphatic hydrops has not been realized (Hornibrook et al., 2016). Although it can be measured by a ET electrode the responses are at least one quarter the magnitude of those obtained by a TT electrode.

ET electrodes are significantly inferior for measuring tone burst responses. Until the signal-to-noise ratio problem of ET electrodes is solved, TT recordings are of greater magnitude and accuracy.

An analysis of 128 Meniere's disease studies (Thorpe et al., 2003) found that the AAO-HNS 1995 definitions were misapplied in $50 \%$ of cases, implying that symptom-only

\section{REFERENCES}

Al-momani, M. O., Ferraro, J. A., Gajewski, B. J., and Ator, G. (2009). Improved sensitivity of electrocochleography in the diagnosis of Meniere's disease. Int. J. Audiol. 48, 811-819. doi: 10.3109/14992020903019338

Arenberg, I. K., Gibson, W. P. R., Hohmann, D., and Mihalco, L. L. (1993). "International standards for transtympanic electrocochleography," in ECoG, $O A E$ and Intraoperative Monitoring, ed D. Hohmann (Amsterdam; New York, NY: Kugler), 115-118.

Aso, S., Watanabe, Y., Mizukoshi, K. (1991). A clinical study of electrocochleography in Meniere's disease. Acta Otolaryngol. 111, 44-52.

Barber, H. O., Pennington, C., Pulec, J. L., Schuknecht, H. F., Tabor, J. R., and McCabe, B. F. (1972). Committee on Hearing and Equilibrium. Meniere's disease: criteria for diagnosis and evaluation of therapy for reporting. Trans. Am. Acad. Opthalmol. Otolaryngol. 76, 1462-1464.

Bohlen, H. K. H., Arenberg, I. K., and Gibson, W. P. R. (1991). "Diagnostic reliablility of electrocochleography for hydrops-ear canal/tympanic membrane versus transtympanic electrode placement," in Surgery of the Inner Ear, ed D. Hohmann (Amsterdam; New York: Kugler), 269-280.

Camilleri, A. E., and Howarth, K. L. (2001). Prognostic value of electrocochleography in patients with unilateral Meniere's disease undergoing saccus surgery. Clin. Otolaryngol. 26, 257-260. doi: 10.1046/j.0307-7772.2001.00468.x

Chertoff, M., Lichtenham, J., and Willis, M. (2010). Click- and chirp-evoked human compound action potentials. J. Acoust. Soc. Am. 127, 2992-2996. doi: $10.1121 / 1.3372756$

Chung, W.-H., Cho, D.-Y., Choi, J.-Y., and Hong, S. H. (2004). Clinical usefulness of extratympanic electrocochleography in the diagnosis of Meniere's disease. Otol. Neurotol. 25, 144-149. doi: 10.1097/00129492-200403000-00011

Claes, G. M. E., De Valck, C. F., Van de Heyning, P., and Wuyts, F. L. (2011). The Meniere's disease index: and objective correlate of Meniere's disease, based on audiometric and electrocochleographic data. Otol. Neurotol. 32, 887-892. doi: 10.1097/MAO.0b013e318219ff9a

Coats, A. C. (1981a). The summating potential and Meniere's disease. I. Summating potential amplitude in Meniere's ears and non-Meniere's ears. Arch. Otolaryngol. 107, 199-208. doi: 10.1001/archotol.1981.00790400001001 criteria are unreliable and can result in underdiagnosis and overdiagnosis. Reliance on a symptom-only diagnosis, based on a pure tone audiogram, has the jeopardy that studies are likely to include patients who do not have the disorder, and to exclude some who do.

Of all investigative tests transtympanic tone burst EcochG remains the simplest, and most sensitive test to diagnose cochlear hydrops to confirm a diagnosis of Meniere's disease. There is agreement that a response of not $<-3 \mathrm{mV}$ is diagnostic for endolymphatic hydrops (Dauman and Aran, 1991; Gibson, 1991, 2005, 2009; Conlon and Gibson, 2000; Claes et al., 2011). Clear, reliable tone burst responses can only be achieved at $100 \mathrm{dbnHL}$, which cannot be achieved by newer model audiology evoked response systems.

As was once for electrocardiography there is an urgent need for universal agreement on equipment specifications (Hohmann et al., 1991; Arenberg et al., 1993; Wuyts et al., 1997), which for the EcochG should produce $100 \mathrm{dBnHL}$ tone bursts.

\section{AUTHOR CONTRIBUTIONS}

The author confirms being the sole contributor of this work and approved it for publication.
Coats, A. C. (1981b). Meniere's disease and the summating potential. II. Vestibular test results. Arch. Otolaryngol. 107, 263-270. doi: 10.1001/archotol.1981.00790400001001

Conlon, B., and Gibson, W. P. R. (1999). Meniere's disease: the incidence of hydrops in the contralateral ear. Laryngoscope 109, 1800-1802. doi: 10.1097/00005537-199911000-00014

Conlon, B. J., and Gibson, W. P. R. (2000). Electrocochleography in the diagnosis of Meniere's disease. Acta Otolaryngol. 120, 480-483. doi: 10.1080/000164800750045965

Dallos, P., Schoeny, Z. G., and Cheatham, M. A. (1972). Cochlear summating potentials: descriptive aspects. Acta Otolaryngol. 302(Suppl.), 1-46.

Dauman, R., and Aran, J.-M. (1991). "Electrocochleography and the diagnosis of endolymphatic hydrops: clicks and tone bursts," in Inner Ear Surgery, ed I. K. Arenberg (Amsterdam; New York, NY: Kugler), 123-133.

Dauman, R., Aran, J. M., de Sauvage, C., and Portmann, M. (1998). Clinical significance of the summating potential in Meniere's disease. Am. J. Otol. 9 , $31-38$.

Dauman, R., Aran, J.-M., and Portmann, M. (1986). Summating potential and water balance in Meniere's disease. Ann. Otol. Rhinol. Laryngol. 95, 389-395. doi: $10.1177 / 000348948609500413$

Davis, H., Fernandez, C., and McAuliffe, D. R. (1950). The excitatory process in the cochlea. Proc. Natl. Acad. Sci. U.S.A. 36, 580-587. doi: 10.1073/pnas.36.10.580

Dornhoffer, J. L., and Arenberg, I. K. (1993). Diagnosis of vestibular Meniere's disease with electrocochleography. Am. J. Otol. 14, $161-164$.

Eggermont, J. J. (1979). Summating potentials in Meniere's disease. Arch. Otorhinolaryngol. 222, 63-75. doi: 10.1007/BF00456340

Ferraro, J. A., Thedinegr, B. S., Mediavilla, S. J., and Balckwell, W. L. (1994) Human summating potential to tone bursts: observations on tympanic membrane versus promonontory recordings in the same patients. J. Am. Acad. Audiol. 5, 24-29.

Ferraro, J. A., and Tibbils, P. (1999). SP/AP area ratio in the diagnosis of Meniere's disease. Am. J. Audiol. 8, 21-27. doi: 10.1044/1059-0889(1999/001)

Ferraro, Murphy, and Ruth, R. A. (1986). A comparative study of electrodes used in extratmp electrocohleography. Semin. Hear. 7, 279-286. doi: 10.1055/s-0028-1091464 
Filipo, R., Cordier, M., Barbara, M., and Bertoli, G. A. (1997). Electrocochleographic findings: Menière's disease versus sudden sensorineural hearing loss. Acta Otolaryngol. Suppl. 526, 21-23.

Gibson, W. P. R. (1978). "Electrocochleography (EcochG)," in Essentials of Clinical Electric Response Audiometry (London: Churchill Livingtson), 69.

Gibson, W. P. R. (1991). "Electrocochleography: a comparison of clicks versus tone bursts in the diagnosis of endolymphatic hydrops," in Inner Ear Surgery, ed I. K. Arenberg (Amsterdam; New York, NY: Kugler), 281-285.

Gibson, W. P. R. (1993). "A comparison of clicks versus tone bursts in the diagnosis of endolymphatic hydrops," in ECoG, OAE and Intraoperative Monitoring, ed D. Hohmann (Amsterdam; New York, NY: Kugler), 55-59.

Gibson, W. P. R. (2005). "The role of transtympanic electrocochleography in the diagnosis of Meniere's disease: a comparison of and $1 \mathrm{kHz}$ tone burst stimuli," in Meniere's Disease and Inner Ear Homeostasis Disorders, ed D. J. Lim (Los Angeles, CA: House Ear Institute), 140-142.

Gibson, W. P. R. (2009). A comparison of two methods of using transtympanic electrocochleography for the diagnosis of Meniere's disease: click summating potential/action potential ratio measurements and tone burst summating potential measurement. Acta Otolaryngol. 129, 38-42. doi: 10.1080/00016480902729843

Gibson, W. P. R., Moffat, D. A., and Ramsden, R. T. (1977). Clinical electrochleography in the diagnosis and management of Meniere's disorder. Audiology 16, 389-401. doi: 10.3109/00206097709071852

Gibson, W. P. R., Prasher, D. K., and Kilkenny, G. P. G. (1983). Diagnostic significance of transtympanic electrocochleography in Meniere's disease. Ann. Otol. Rhinol. Laryngol. 92, 155-159. doi: 10.1177/000348948309200212

Hohmann, D. H., Gibson, W. P. R., Arenberg, K. I., Dauman, R., and Bohlen, H. K. H. (1991). "International standards of transtympanic electrocochleography recordings," in Inner Ear Surgery, ed I. K. Arenberg (Amsterdam; New York, NY: Kugler), 249-252.

Hornibrook, J., Bird, P., Flook, E., and O’Beirne, G. A. (2016). Electrocochleography for the diagnosis of Ménière's disease: the wrong stimulus. Otol. Neurotol. 37, 1677-1678. doi: 10.1097/MAO.0000000000001206

Hornibrook, J., Coates, M., Goh, T., and Bird, P. (2010a). MRI inner ear imaging for Meniere's disease. N. Z. Med. J. 123, 64-68.

Hornibrook, J., Flook, E., Greig, S., Babbage, M., Goh, T., Coates, M., et al. (2015). MRI inner ear imaging and tone burst electrocochleography in the diagnosis of Meniere's disease. Otol. Neurotol. 36, 1109-1114. doi: 10.1097/MAO.0000000000000782

Hornibrook, J., George, P., and Gourley, J. (2010b). Vasopressin in definite Meniere's disease with positive eletrocochelographic findings. Acta Otolaryngol. $13,613-617$.

Hornibrook, J., George, P., Spellerberg, M., and Gourley, J. (2011). HSP70 antibodies in 80 patients with "clinically certain" Meniere's disease. Ann. Otol. Rhinol. Laryngol. 120, 651-655. doi: 10.1177/000348941112001004

Hornibrook, J., Kalin, C., Lin, E., O’Beirne, G. A., and Gourley, J. (2012). Transtympanic electrocochleography for the diagnosis of Ménière’s disease. Int. J. Otolaryngol. 2012:852714. doi: 10.1155/2012/852714

Ikino, C. M. Y., and de Almeida, E. R. (2006). Summating potetntialaction potential waveform and width in the diagnosis of Meniere's disease. Laryngoscope 116, 1766-1769. doi: 10.1097/01.mlg.0000227976.43352.61

Iseli, C., and Gibson, W. P. R. (2010). A comparison of three methods of using transtympanic electrocochleography for the diagnosis of Meniere's disease: click summating potential measurements, tone burst summating potential measurements amplitude measures, and biasing of the summating potential with a low tone. Acta Otolaryngol. 130, 95-101. doi: 10.3109/00016480902858899

Johnson, S.-A., O’Beirne, G. A., Lin, E., Gourley, J., and Hornibrook, J. (2016). oVEMPs and cVEMPs in patienst with "clinically certain Meniere's disease." Acta Otolaryngol. 136, 1029-1034. doi: 10.1080/00016489.2016.1175663

Kim, H. H., Kumar, A. K., Battista, R. A., and Wiet, R. J. (2005). Electrocochleography in patients with Meniere's disease. Am. J. Otolaryngol. 26, 126-131. doi: 10.1016/j.amjoto.2004.11.005

Lopez-Escamez, J. A., Carey, J., Chung, W.-H., Goebel, J. A., Magnusson, M., Mandalà, M., et al. (2015). Diagnostic criteria for Menière's disease. J. Vest. Res. 25, 1-7. doi: 10.3233/VES-150549

Marcio, C., Ikino, Y., and de Almeida, R. (2006). Summating potential-action potential waveform amplitude and width in the diagnosis of Meniere's disease. Laryngoscope 116, 1766-1769. doi: 10.1097/01.mlg.0000227976.43352.61
Moffat, D. A., Gibson, W. P. R., Ramsden, A. W., and Booth, J. B. (1978). Transtympanic electrocochleography using glycerol dehydration. Acta Otolaryngol. 85, 158-166. doi: 10.3109/00016487809111922

Monsell, E. M., Balkany, T. A., Gates, G. A., Goldenberg, R. A., Meyerhoff, W. L., and House, J. W. (1995). Committee on hearing and equilibrium guidelines for the diagnosis and evaluation of therapy in Meniere's disease. Otolaryngol. Head Neck Surg. 113, 181-185. doi: 10.1016/S0194-5998(95) 70102-8

Mori, N., Asai, H., and Matsunaga, T. (1987). Diagnostic value of extratympanic electrocochleography in Menière's disease. Audiol. 26, 103-110.

Nakashima, T., Naganawa, S., Katayama, N., Teranishi, M., Nakata S., Sugiura, M., et al. (2009). Clinical significance of endolympahtic imaging after intratympanic gadolinium injection. Acta Otolaryngol. 129, 9-14. doi: 10.1080/00016480902729801

Nguyen, L. T., Harris, J. P., and Nguyen, Q. T. (2010). Clinical utility of elctrocochleography in the diagnosis and management of Meniere's disease: AOS and ANS membership survey data. Otol. Neurotol. 31, 455-459. doi: 10.1097/MAO.0b013e3181d2779c

Paparella, M. M. (1984a). Pathogenesis of Meniere's disease and Meniere's syndrome. Acta Otolaryngol. 406(Suppl.), 10-25. doi: 10.1177/00034894840930S406

Paparella, M. M. (1984b). Pathology of Meniere's disease. Ann. Otol. Rhinol. Laryngol. Suppl. 112, 31-35. doi: 10.1177/00034894840930S406

Paparella, M. M., and Mancini, F. (1985). Vestibular Meniere's disease. Otolaryngol. Head Neck Surg. 93, 148-151. doi: 10.1177/019459988509300203

Pender, D. J. (2014). Endolymphatic hydrops and Meniere's disease: a lesion meta-analysis. J. Laryngol. Otol. 128, 859-865. doi: 10.1017/S0022215114 001972

Portmann, M., Le Bert, G., and Aran, J. M. (1967). Potentiels cochleaires obtenus chez l'homme en dehors de toute intervention chirurgicale. Rev. Laryngol. Otol. $88,157-164$.

Pou, A. M., Hirsch, B. E., Durrant, J. D., Gold, S. R., and Kamerer, D. B. (1996). The efficacy of tympanic electrocochleography in the diagnosis of endolymphatic hydrops. Am. J. Otol. 17, 607-611.

Roland, P. S., and Roth, L. (1997). Interinterpreter variability in determining the SP/AP ratio in clinical electrocochleography. Laryngoscope 107, 1357-1361. doi: 10.1097/00005537-199710000-00012

Roland, P. S., Yellin, M. W., Meyerhoff, W. L., and Frank, T. F. (1995). Simultaneous comparison between transtympanic and extratympanic electrocochleography. Am. J. Otol. 16, 444-450.

Ruben, R. J., Bordley, J. E., and Lieberman, A. T. (1961). Cochlear potentials in man. Laryngoscope 71, 1141-1164. doi: 10.1288/00005537-196110000-00001

Sass, K. (1998). Sensitivity and specificity of transtympanic electrocochleography in Meniere's disease. Acta Otolaryngol. 118, 150-156. doi: 10.1080/00016489850154838

Saul, L. J., and Davis, H. A. (1932). Action currents in the central nervous system. I. Action currents of the auditory tracts. Arch. Neurol Pyschol. 28, 1104-1116. doi: 10.1001/archneurpsyc.1932.02240050140009

Schmidt, P. H., Eggermomt, J. J., and Odenthal, D. W. (1974). Study of Meneiere's disease by electrocochleography. Acta Otolaryngol. 36(Suppl.), 75-84. doi: 10.1080/16512251.1974.11675748

Sohmer, H., and Feinmesser, M. (1967). Cochlear action potentials recorded from the external ear in man. Ann. Otol. Rinol. Laryngol. 76, 427-435. doi: $10.1177 / 000348946707600211$

Stopp, P. E., and Whitfeild, I. C. (1964). Summating potentials in the avian cochlea. J. Physiol. (Lond). 175, 45-46.

Takeda, T., and Kakigi, A. (2010). The clinical value of extratympanic electrocochleography in the diagnosis of Meniere's disease. ORL J. Otorhinolaryngol. Relat. Spec. 72, 196-204. doi: 10.1159/000315552

Teas, D. C., Eldrege, D. H., and Davis, H. (1962). Cochlear responses to acoustics transients: an interpretation of the whole action potentials. J. Acoust. Soc. Am. 34, 1438-1459. doi: 10.1121/1.1918366

Thorpe, M. A., Shehab, Z. P., Bance, M. L., and Rutka, J. A. (2003). The AAOHNS Committee on Hearing and Equilibrium guidelines for the diagnosis and evaluation of therapy for Meniere's disease: have they been applied in the published literature in the last decade? Clin. Otolaryngol. 28, 173-176. doi: 10.1046/j.1365-2273.2003.00687.x

von Bekesy, G. (1952). D-C resting potentials in the cochlea partition. J. Acoust. Soc. Am. 24, 72-76. doi: 10.1121/1.1906851 
Wever, E. G., and Bray, C. W. (1930). Action currents in the auditory nerve in response to acoustic stimulation. Proc. Natl. Acad. Sci. U.S.A. 16, 344-350. doi: $10.1073 /$ pnas.16.5.344

Wuyts, F. L., Van de Heyning, P., Spaendonck, M. P., and Molenberghs, G. (1997). A review of electrocochleography: instrumental settings and meta-analysis or criteria for diagnosis of endolymphatic hydrops. Acta Otolaryngol. Suppl. 526, 14-20. doi: 10.3109/00016489709124014

Yoshie, N. (1968). Auditory action potentials to click in man. Laryngoscope 178, 198-215. doi: 10.1288/00005537-196802000-00002

Zerlin, S. (1969). Travelling-wave velocity in the human cochlea. J. Acoust. Soc. Am. 46, 1011-1016. doi: 10.1121/1.1911792

Ziylan, F., Smeeing, D. P. J., Stegeman, I., and Thomeer, H. G. (2016). Click stimulus electrocochleography versus MRI with intratympanic contrast in Meniere's disease: a systematic review. Otol. Neurotol. 37, 421-427. doi: 10.1097/MAO.0000000000001021
Zwicker, E., and Fast, L. (1972). On the development of the critical band. J. Acoust. Soc. Am. 52, 699-702. doi: 10.1121/1.19 13161

Conflict of Interest Statement: The author declares that the research was conducted in the absence of any commercial or financial relationships that could be construed as a potential conflict of interest.

Copyright (C) 2017 Hornibrook. This is an open-access article distributed under the terms of the Creative Commons Attribution License (CC BY). The use, distribution or reproduction in other forums is permitted, provided the original author(s) or licensor are credited and that the original publication in this journal is cited, in accordance with accepted academic practice. No use, distribution or reproduction is permitted which does not comply with these terms. 